\title{
From Editor-in-Chief
}

In starting 2012 publication activity, I would like to proudly report the successive growth of our all-electronic and peer-reviewed journal, The IEICE Electronics Express (ELEX). The Electronics Society of the Institute of Electronics, Information and Communication Engineers (IEICE) kicked out the new journal, ELEX, on April 10, 2004. I am very pleased to know that numbers of accessing to and downloading from our ELEX website were significantly increased. In the volume 8 for the year 2011 we presented 24 issues. The total of 320 papers were published. The contributors are quite international. Namely, the number of countries/areas where the first authors of published papers belong is as large as 25. As of December 20, 2011, the number of submissions totally amounts to 1,095 . It was $122 \%$ increase over the previous year. The rate of acceptance is approximately $30 \%$. The total number of 268,215 was accessed to our ELEX website and 87,190 papers were downloaded from the website in 2011.

We understand such international recognition of ELEX is owing to the fact that papers are rapidly published: The period from paper submission (the moment of uploading manuscript files by authors) to publishing is 10 calendar days in the fastest case, 63 days on the average. This good record was achieved by the collaboration of reviewers and authors, both of whom are conscious of the importance of rapid publication. In addition the endeavor of staffs in the IEICE Publishing Office and the Editorial Committee members should not be forgotten.

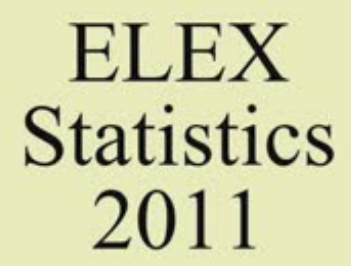

Fig. 1. Statistics of ELEX in 2011. A movie file is embedded. Adobe Reader 6.0 (or later) and Quick Time Player 6.0 (or later), both are freewares, should be installed for playing the movie. 
Another advantage of ELEX also comes from the nature of all-electronic publication. The authors can present their results in impressive manners using multicolor figures or movie files. You can find a large number of papers with multicolor figures. On the other hand, the usage of movie files is not yet fully exploited. One paper with movie files embedded has already been published. We hope that the number of such papers will increase in the subsequent volumes. Figure 1 is attached one demonstration of movie files.

Furthermore for the benefit of the readers it was determined that main bodies of the respective files, provided in PDF formats, are accessible without identification process for now. The readers are, however, kindly advised to consider registration at IEICE website for receiving free e-mail alerts, which provide registered users with hyperlinks to papers in the latest issues.

I would also like to give you several announcements about activities in 2011.

- A new category of papers, "Review Papers" was created. Review papers are published every three months. The topics and authors are selected by ELEX Editorial Committee. In the last volume, 2 review papers on $\mathrm{THz}$ technology and 3 on optical communication technology has been published. The field covered by ELEX is getting wider and wider. Accordingly, it becomes difficult for the readers to follow the research trend in the filed out of their own area. We believe review papers will expand the reader's attention and trigger reader's researches in a new field or with a new concept.

- The exemption from article charge payment program continues; authors can apply to the program, and ELEX editorial committee judges whether the paper meets the qualification or not. Not more than twenty papers earn this privilege.

- As has already been announced on the website, I would like to inform you that ELEX has been selected for coverage in Thomson Scientific (formerly known as Thomson ISI) products and services.

Beginning with Vol.2, No.1 2005, this publication will be indexed and abstracted in:

-Science Citation Index Expanded (also known as SciSearch®)

-Journal Citation Reports/Science Edition

-Current Contents $囚 /$ Engineering Computing and Technology

In addition, the first impact factor (IF) for ELEX was released in 2008, and the current IF for 2011 is 0.43 .

- We ELEX Editorial Committee are pleased to decide ELEX Best Paper Award 2010, which was given to the best quality and valuable paper.

Finally, I would like to make two important announcements about editorial issues. One is the revision of the payment structure. A new fee scale for 
the publication will be introduced in June 2012. In the new structure, an additional publication fee is imposed on manuscripts longer than regular publication pages. The other is about a future revision of the scope for submission. The scope of ELEX is going to be revised on March $1^{\text {st }}, 2012$ in accordance with the launch of "IEICE Communication Express (ComEX)" on June $1^{\text {st }}, 2012$. The details of the revisions on publication fee and on scopes will be announced soon. I thank you very much in advance for your understanding and cooperation.

We know that your suggestions and comments are quite useful for improving ELEX services and for making ELEX more attractive for all engineers in advanced electronics. We appreciate any kind of suggestions and comments.

We continue to make every effort so that ELEX plays a more important role in the accelerated progress of electronics and related science serving for the welfare of humankind.

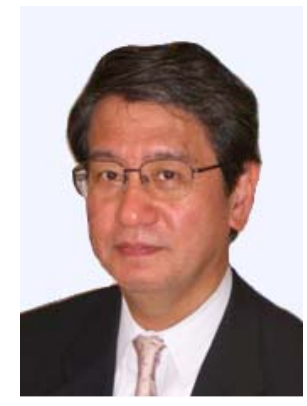

Masayuki Izutsu

Editor-in-Chief

IEICE Electronics Express 


\section{ELEX editorial committee members list (As of January 10, 2012)}

\section{Editor-in-chief}

Masayuki IZUTSU

\section{Editors}

Satoshi IWAMOTO

Koji FUJII

\section{Associate editors}

\author{
Photonic devices, circuits and systems \\ Yoshinari AWAJI \\ Tetsuro KOMUKAI \\ Hiroshi MURATA \\ Masataka NAKAZAWA \\ Takahiro NUMAI \\ Misuzu SAGAWA \\ Kristian E. STUBKJAER \\ Andrew M. WEINER \\ Ming C. WU \\ National Institute of Information and Communications \\ Technology(NICT) \\ Nippon Telegraph and Telephone Corporation (NTT) \\ Osaka University \\ Tohoku University \\ Ritsumeikan University \\ Hitachi Ltd. \\ Technical University of Denmark \\ Purdue University \\ University of California, Los Angeles
}

The University of Tokyo

Nippon Telegraph and Telephone Corporation (NTT)

\section{Electromagnetic theory, microwave and millimeter-wave devices, circuits and}

\section{systems}

Kazuhiko HONJO

Futoshi KUROKI

Shoichi NARAHASHI

Jung-Woong RA

Alwyn J. SEEDS

Naoki SHINOHARA

Kohji WADA

Akio WAKEJIMA

Mitsuhiro YOKOTA

\section{Electron devices and integrated circuits}

Tsuyoshi FUNAKI

Tatsuya HIROSE

Toshiki KANAMOTO

Won-Seong LEE

Kristin De MEYER

Daisuke UEDA

SungMin YOON

\section{Integrated circuits}

Tohru ISHIHARA

Hiroshi IWAI

Seiichiro MORO

Shigehito SAIGUSA

Alexandre SCHMID

Ken TAKEUCHI

Tsuneo TSUKAHARA

Mamoru UGAJIN

Michio YOKOYAMA

Toshihiko YOSHIMASU

Shingo YOSHIZAWA
The University of Electro-Communications

Kure National College of Technology

NTT DOCOMO, INC.

Gwangju Institute of Science and Technology (GIST)

University College London

Kyoto University

The University of Electro-Communications

Nagoya Institute of Technology

University of Miyazaki
Osaka University

Fujitsu Laboratories Ltd.

Renesas Electronics Corporation

Samsung Electronics Co., Ltd.

The Interuniversity Microelectronics Center

Panasonic Corporation

Kyung Hee University

Kyoto University

Tokyo Institute of Technology

University of Fukui

Toshiba Corporation

Swiss Federal Institute of Technology

The University of Tokyo

The University of Aizu

Nippon Telegraph and Telephone Corporation (NTT)

Yamagata University

Waseda University

Hokkaido University 


\section{Micro- or nano-electromechanical systems}

$\begin{array}{ll}\text { Masayoshi ESASHI } & \text { Tohoku University } \\ \text { Gen HASHIGUCHI } & \text { Shizuoka University } \\ \text { Hidekuni TAKAO } & \text { Kagawa University }\end{array}$

Functional devices and materials

(Nanotechnology)

Tomoji KAWAI Osaka University

\section{(Superconducting electronics)}

Akinobu IRIE

Utsunomiya University

\section{(Storage technology)}

Tetsuhiko MUROI Japan Broadcasting Corporation

\section{Science and engineering for electronics}

Kosin CHAMNONGTHAI King Mongkut's University of Technology Thonburi Mitoshi FUJIMOTO

University of Fukui

Hiroo SEKIYA

Chiba University

Hiroyoshi YAMADA

Niigata University

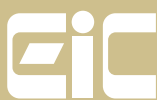

(c) IEICE 2012 